\title{
Analysis of the 'A72' Peach Tree Growth Habit and Its Inheritance in Progeny Obtained from Crosses of 'A72' with Columnar Peach Trees
}

\author{
Dongyan Hu \\ United States Department of Agriculture, Agricultural Research Service, Appalachian Fruit Research \\ Station, 2217 Wiltshire Road, Kearneysville, WV 25430 and Beijing Botanical Garden, Wofosi Road, \\ Beijing, 100093, China \\ Ralph Scorza ${ }^{1}$ \\ United States Department of Agriculture, Agricultural Research Service, Appalachian Fruit Research \\ Station, 2217 Wiltshire Road, Kearneysville, WV 25430
}

\begin{abstract}
AdDitional INDEX words. Prunus persica, forked-branch, lateral branching, late flowering, breeding, dwarf, semidwarf
ABstract. Since the first report of the 'A72' semidwarf peach [Prunus persica (L.) Batsch] tree in 1975, no new information has become available on this genotype. We evaluated the growth habit and verified the inheritance of 'A72' in a population of 220 progeny derived from self-pollination. Detailed tree and branch measurements revealed a unique forked-branch (FBR) character of the 'A72' (Nn) phenotype. The progeny segregated into $1 \mathrm{NN}: 2 \mathrm{Nn}: 1 \mathrm{nn}$. $\mathrm{NN}$ trees were indistinguishable from standard peach trees, $N n$ were FBR, and $n n$ were dwarf. Hybrids between 'A72' and columnar (brbr) peach trees confirmed that FBR is inherited as a monogenic trait that appears to express incomplete dominance. 'A72' $(\mathrm{Nn})$ trees were later blooming than sibling $N N$ trees. The relationship (linkage or pleiotropy) between the growth habit of ' $\mathrm{A} 72$ ' and late bloom is not known. The structure of 'A72' trees presents new opportunities to breeder/geneticists, physiologists, and horticulturists to further explore the plasticity of peach tree growth and architecture that can be achieved through breeding. Applications of the 'A72' growth habit for commercial fruit production and as an ornamental, particularly in the dwarf form $(n n)$ and in combination with the columnar tree (brbr) form, present opportunities that await exploration.
\end{abstract}

Dwarf peach trees have been studied since the first recorded description by Monceau in 1786 (in Monet and Salesses, 1975). In 1867, Strong (1867) and Hooper (1867) described dwarf peach tree phenotypes. Conners (1928) observed semidwarf trees in progeny from self-pollinated 'Elberta', and concluded that the trait was recessive. Since then, three dwarf genotypes have been identified. Lammerts (1945) obtained dwarf trees in $F_{2}$ populations from the cross of 'Chinese Dwarf' and a standard growth form and concluded that this dwarf type is monogenic and recessive. This dwarf, know as the "brachytic" dwarf ( $d w d w)$ type is characterized by short internodes and large leaves. Lammerts (1945) reported a semidwarf peach trait ("bushy") that was inherited as a double recessive gene (bulbulbu2bu2). A semidwarf mutant 'A72' was described by Monet and Salesses (1975) that differs phenotypically and genetically from the commonly recognized "brachytic dwarf" described by Lammerts (1945). The 'A72' dwarf trait $(n n)$ is incompletely dominant with the heterozygote expressing as a semidwarf tree. Gradziel and Beres (1993) reported an apparent mutant phenotype in a seedling of an open pollination of a clingstone breeding line. This tree ('SD22-59') resembled the 'A72' dwarf and the segregation of growth habits in progeny of 'SD22-59' $\times$ standard growth habit varieties (1 semidwarf:1 standard growth) was also suggestive of the phenotype pro-

Received for publication 12 Sept. 2008. Accepted for publication 12 Jan. 2009. We gratefully acknowledge excellent technical support by Mark Demuth, statistical analyses provided by John Philips, and plant material provided by William R. Okie.

${ }^{1}$ Corresponding author. E-mail: ralph.scorza@ars.usda.gov. duced by the 'A72' mutation. To our knowledge, there has been no study that characterizes the growth or architecture of the 'A72' dwarf ( $(n n)$ or semidwarf $(\mathrm{Nn})$, nor is there information on the interaction of the 'A72' growth type with other growth types, for example columnar (brbr). In this study, we characterize the morphological expression of this growth habit in segregating progenies and its interaction with columnar (pillar) peach.

\section{Materials and Methods}

The 'A72' genotype used in this study was obtained from R. Monet through W.R. Okie (U.S. Department of Agriculture, Agricultural Research Service, Byron GA) in 1996.

\section{Segregation studies}

Self-pollination of 'A72' was carried out in 2004 by covering trees with parachutes from prebloom until petal fall (Werner and Cain, 1985). Seeds were removed from the endocarp and were stratified at $5{ }^{\circ} \mathrm{C}$ for about $60 \mathrm{~d}$. A total of 338 self-pollinated seeds were collected. Two hundred forty-six seeds germinated ( $72 \%$ germination). They were planted in a greenhouse in Jan. 2005 in Metro Mix 500 (Sungro, Bellevue, WA) medium and were fertilized with a dilute $10 \mathrm{~N}-4.4 \mathrm{P}-8.3 \mathrm{~K}$ solution. In the greenhouse, these seedlings were classified by height, which was dwarf (presumed $n n$ ), intermediate (presumed $N n$ ), and tall seedlings (presumed $N N$ ). Two hundred twenty-eight of these seedlings were planted in the field (93\%). One hundred sixty-four were planted in the field in July 2005 at a spacing of $1.2 \times 6 \mathrm{~m}$ to study the segregation of 'A72' progeny. In the field, trees were fertilized with $325 \mathrm{~kg} \cdot \mathrm{ha}^{-1}$ of 
$10 \mathrm{~N}-4.4 \mathrm{P}-8.3 \mathrm{~K}$ in the spring of the first year and with urea at $40 \mathrm{~kg} \cdot \mathrm{ha}^{-1} \mathrm{~N}$ in the following years. Herbicides, insecticides, and fungicides were applied as needed during the growing seasons. Survival in the field was $95 \%$. The canopy heights of these trees were measured. Visual rating of branching characteristics and flowering time were evaluated independently by three observers in the field in 2008. Flowering time was based on the estimation of the ratio of fully opened to unopened flowers.

\section{Growth habit assessment}

Tree measurement. From the 228 'A 72 ' seedlings described above, 16 trees of each 'A72' seedling class ( $N N$, $\mathrm{Nn}$, and $n n$ ), based on height, were selected for inclusion in an adjacent field plot. At the time of selection in the greenhouse, hybrids from standard sized (ST) peach tree crosses were $\approx 65$ $\mathrm{cm}$ in height. 'A72' seedlings in this height range were considered $N N$. Seedlings that were $60 \%$ to $70 \%$ of this height were considered $N n$. Presumed $n n$ trees were significantly smaller and clearly dwarf in their growth type. These selected trees were not planted out with the seedlings in July 2005 but spent that first growing season in the greenhouse and were field planted in Nov. 2005 at a spacing of $4 \times 5 \mathrm{~m}$ in a randomized complete block design with four four-tree replications (16 trees) of each seedling type (dwarf, intermediate, and tall). This field plot design also included brachytic dwarf $(d w d w)$ seedlings (16 trees) from self-pollination of 'Valley Red' (Hansche, 1989) as a dwarf (DW) peach tree reference. Sixteen ST trees from open pollination of 'Bounty' were included as a standard peach tree growth habit reference. The ST trees were transferred from the greenhouse to the field in May 2006. Due to damage or death of trees caused by ground hog (Marmota monax L.) feeding, herbicide, and/or brush mower damage, 10 of the 16 replicate trees of each growth type were selected for measurement in June 2007. Fertilization and pest control were as described above. Measurements followed the procedures of Scorza (1984) and Scorza et al. (1989), and were tree height, canopy diameter, at maximum width of the tree, trunk diameter, at or near soil level, and other measurements, as follows.

LENGTH OF FIRST- AND SECOND-ORDER BRANCHES. First-order branches (two branches per tree) were identified as those arising directly from scaffold branches or directly from the trunk; second-order branches arose from first-order branches. Selected first-order branches were between 22 and $26 \mathrm{~mm}$ in diameter.

Nodes PER CENTIMETER ON SECOND-ORDER BRANCHES. Six branches per tree were randomly selected for measurement. The total number of nodes on $20 \mathrm{~cm}$ of branch, measured at midbranch, for $N n, N N$, and ST, and total number of nodes on the branches of $d w d w$ and $n n$ trees were counted. This measurement provided internode length.

Number of LATERAL BRANCHES. This measurement consisted of the number of first-order branches per $30 \mathrm{~cm}$ of trunk or scaffold and the number of second-order branches per $20 \mathrm{~cm}$ of first-order branch for $N n, N N$, and ST. Because $d w d w$ and $n n$ trees were smaller, the number of laterals was counted per $10 \mathrm{~cm}$ of supporting branch.

BRANCH ANGLE. Branch angle is the angles from the trunk or scaffold of two first-order branches and the angle from firstorder branch for six second-order branches per tree.

LEAF SIZE. The length and width at the widest dimension were measured on six young fully expanded leaves sampled randomly throughout the canopy of each tree.
DETAILED FIRST-ORDER BRANCH MEASUREMENT. The later field planting date of ST trees compared with 'A72' progeny (May 2006 and Nov. 2005, respectively) delayed the growth of ST trees such that direct comparisons of total tree growth were not possible. Comparisons were made by selecting branches of the same branching order and of the same basal diameter within the tree types $N N, N n$, and ST. Two first-order branches (arising from the trunk or major scaffold) per tree were sampled from 10 randomly selected trees from each of the three phenotypes. The mean diameter of sampled branches at the point of removal from the tree was $23 \mathrm{~mm}$. Measurements made in Apr. 2008 were as below.

Branch Length. This measurement consisted of the total length of each selected branch.

LATERAL LENGTH AND NUMBER. Laterals were counted and measured at $10-\mathrm{cm}$ intervals through the entire length of the first-order supporting branch beginning at the apex of the supporting branch. Laterals less than $6 \mathrm{~cm}$ in length were not included in this measurement.

Sublateral number. This measurement is the number of sublaterals produced on each lateral.

Node DENSITY. Node density is the number of nodes per $10 \mathrm{~cm}$ of branch length from the base of the branch to the apex.

Hybridization of 'A72' $\times$ COlumnar Peach trees. Controlled hybridization following the general hybridization method as described in Scorza and Sherman (1996) was performed in 2004 between selection KV981705, a red leaf tall columnar peach tree (presumed $N N$ brbr Grgr), and selection KV000056, a green leaf short stature columnar tree with other obvious traits of 'A72' (presumed $\mathrm{Nn}$ brbr grgr) (Fig. 1). Seeds of this cross were collected, stratified, germinated, and planted as for the 'A72' self-pollinated trees described above. Germination percentages were $95 \%$ to $100 \%$ for all crosses except for KV000056 × KV930465, which had $74 \%$ germination. The seedlings were field planted in June 2005 and all survived. In the 2007 growing season, canopy height, trunk diameter, and leaf color were recorded for 47

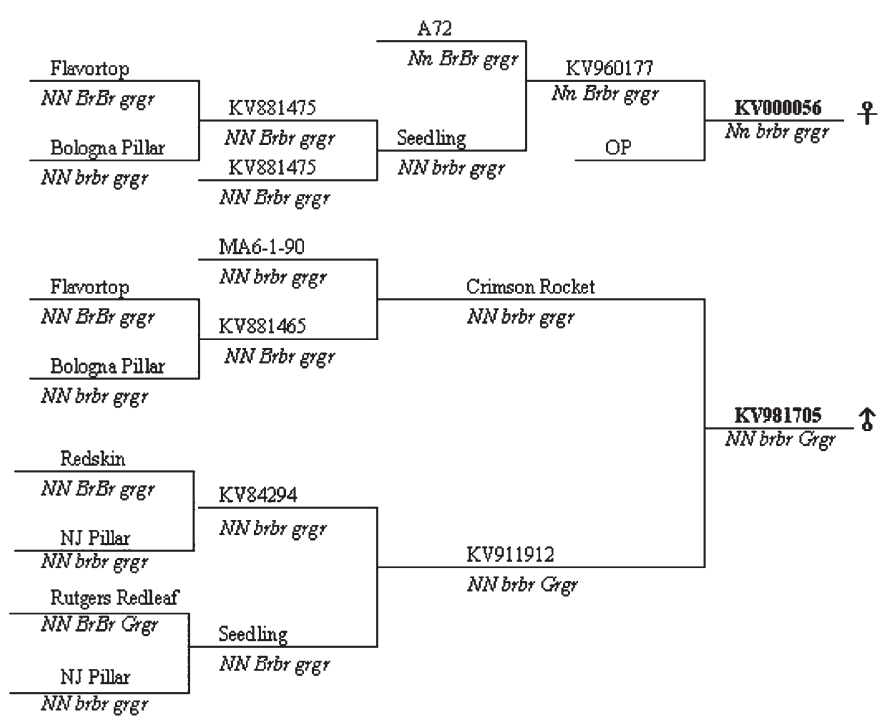

Fig. 1. Pedigree and proposed genotypes of the 'A72' $(\mathrm{Nn}) \times$ columnar $(\mathrm{brbr})$ peach tree cross evaluated for the interaction of growth habit and for leaf color $($ red $=G r$, green $=g r g r)$ in this study. 
seedling trees. In Spring 2008, branching characteristics and bloom time were evaluated as described above.

Additional populations, smaller in size, were also used in this study to confirm the interaction between pillar and 'A72'. These crosses were made between siblings of KV000056 and KV981705 and were: KV000056 × KV930465 (presumed $N n$ brbr grgr $\times$ NN brbr grgr: 24 trees); KV000009 $\times$ KV980330 (presumed $N n$ brbr $\operatorname{grgr} \times N N$ brbr $\operatorname{grgr}: 12$ trees); an unnumbered 'A72' $\times$ pillar hybrid seedling $\times$ KV930408 (presumed $N$ n brbr grgr $\times$ NN brbr grgr: 7 tress); an unnumbered 'A72' $\times$ pillar seedling $\times$ KV981705 (presumed Nn brbr grgr $\times$ NN brbr Grgr: 8 trees); KV000023 $\times$ KV 981705 (presumed Nn brbr grgr $\times$ NN brbr Grgr 9 trees); and KV000009 $\times$ KV981705 (presumed $\mathrm{Nn}$ brbr $\mathrm{grgr} \times \mathrm{NN}$ brbr Grgr: 6 trees). Field survival of seedling trees from the six crosses was $99 \%$.

All trees were unpruned except for the removal of dead branches.

STatistical analyses. Chi-square analyses were used to test segregation ratios. Growth data were analyzed by analysis of variance using Proc Mixed of SAS (version 9.1.3; SAS Institute, Cary, NC) software system. Mean separations were performed using the Bonferroni least significant difference technique at $P=0.05$. Discriminant analysis was also performed on the growth data to develop classification rules for the varieties based on the values of the growth variables measured. Growth measurements of DW trees were presented as normal distributions centered at their mean values and using their standard deviations for the respective tree types.

\section{Results}

\section{Growth habit assessment}

NN VERSUS $\boldsymbol{D} W \boldsymbol{W} \boldsymbol{W}$. While the 'A72' ( $n n)$ and the brachytic $(d w d w)$ DW trees are extremely divergent from the other 'A 72 ' seedlings in almost all measured parameters (Table 1), both DW type trees are also visually distinct from each other (Fig. 2). Tree measurements showed that almost all parameters measured differed between the two DW types (Table 1).

Compared with $d w d w$ trees, $n n$ trees were characterized as shorter, narrower, with a smaller trunk diameter, fewer firstorder branches, more but shorter second-order branches, and smaller leaves. The shorter internode length (i.e., the largest number of nodes per centimeter) contributes to the smaller tree size.

The best single variable for separating $d w d w$ and $n n$ types was the average leaf length (LL) (Fig. 3A). The separation rule derived from discriminate analysis is if $\mathrm{LL}<15.36 \mathrm{~cm}$, then the DW type is $n n$, and if $L L>15.36 \mathrm{~cm}$, then the type is $\mathrm{d} w d w$. Because trees do not have leaves during the winter months, other variables that separate the two DW types are canopy diameter and second-order branch length (Fig. 3, B and C). The separation rule using canopy diameter (CD) is if $\mathrm{CD}$ is $<36.8$ $\mathrm{cm}$, then DW type is $n n$, and if CD is $>36.8 \mathrm{~cm}$, then DW is $d w d w$. The separation rule of second-order branch length (SOBL) is if SOBL is $<6.1 \mathrm{~cm}$, then DW type is $n n$, and if SOBL $>6.1 \mathrm{~cm}$, then DW type is $d w d w$.

$N_{N}$ VERSUS $N N$ VERSUS ST. $N n$ was distinct from $N N$ and ST by its shorter branch length and fewer laterals with more sublaterals and longer lateral lengths (Table 2; Fig. 4). Bud density did not differ between tree types except at the basal $10-\mathrm{cm}$ interval $(1-10 \mathrm{~cm})$ and at the 31 to $40 \mathrm{~cm}$ interval where $\mathrm{Nn}$ had a higher bud density (shorter internodes) than ST at 1 to $10 \mathrm{~cm}$
Table 1. Comparison of growth characteristics of dwarf peach trees $(d w d w$ and $n n)$, and of nondwarf peach trees $(N n$ and $N N)$. Each mean is the result of measurements taken from 10 2-year trees in June 2007. Mean separations within dwarf and nondwarf trees by the Bonferroni least significant difference test.

\begin{tabular}{|c|c|c|c|c|}
\hline \multirow[b]{2}{*}{ Growth characteristics } & \multicolumn{4}{|c|}{ Tree type } \\
\hline & $d w d w$ & $n n$ & $\mathrm{Nn}$ & $N N$ \\
\hline Tree height & $40.5 \mathrm{a}$ & $25.3 \mathrm{~b}$ & $144.6 \mathrm{~b}$ & $168.1 \mathrm{a}$ \\
\hline Canopy diameter ${ }^{z}$ & $55.1 \mathrm{a}$ & $28.0 \mathrm{~b}$ & $132.8 \mathrm{~b}$ & $150.5 \mathrm{a}$ \\
\hline Trunk diameter ${ }^{\mathrm{y}}$ & $1.8 \mathrm{a}$ & $0.75 \mathrm{~b}$ & $3.2 \mathrm{a}$ & $3.6 \mathrm{a}$ \\
\hline $\begin{array}{l}\text { First-order branch } \\
\text { length }^{\mathrm{x}}\end{array}$ & $15.9 \mathrm{a}$ & $13.8 \mathrm{a}$ & $67.2 \mathrm{a}$ & $71.6 \mathrm{a}$ \\
\hline $\begin{array}{l}\text { Second-order branch } \\
\text { length }^{\mathrm{w}}\end{array}$ & $12.1 \mathrm{a}$ & $3.4 \mathrm{~b}$ & $41.6 \mathrm{a}$ & $43.6 \mathrm{a}$ \\
\hline $\begin{array}{l}\text { Number of first-order } \\
\text { branches }^{v}\end{array}$ & $8.0 \mathrm{a}$ & $3.5 \mathrm{~b}$ & $18.3 \mathrm{a}$ & $17.4 \mathrm{a}$ \\
\hline $\begin{array}{l}\text { Number of second-order } \\
\text { branches }^{\mathrm{u}}\end{array}$ & $4.4 \mathrm{~b}$ & $7.9 \mathrm{a}$ & $11.2 \mathrm{a}$ & $12.5 \mathrm{a}$ \\
\hline $\begin{array}{l}\text { First-order branch } \\
\text { angle }^{t}\end{array}$ & $61 \mathrm{a}$ & $54 \mathrm{a}$ & $53 \mathrm{a}$ & $53 \mathrm{a}$ \\
\hline $\begin{array}{l}\text { Second-order branch } \\
\text { angle }^{\mathrm{s}}\end{array}$ & $38 \mathrm{a}$ & $34 \mathrm{~b}$ & $47 \mathrm{~b}$ & $52 \mathrm{a}$ \\
\hline Nodes per centimeter ${ }^{\mathrm{r}}$ & $1.7 \mathrm{~b}$ & $4.2 \mathrm{a}$ & $0.60 \mathrm{a}$ & $0.53 \mathrm{~b}$ \\
\hline Leaf length ${ }^{\mathrm{q}}$ & $21.6 \mathrm{a}$ & $9.2 \mathrm{~b}$ & $15.6 \mathrm{a}$ & $12.9 \mathrm{~b}$ \\
\hline Leaf width & $3.3 \mathrm{a}$ & $1.8 \mathrm{~b}$ & $3.6 \mathrm{a}$ & $3.4 \mathrm{a}$ \\
\hline
\end{tabular}

${ }^{\mathrm{z}}$ Measured at the maximum width of the tree.

${ }^{y}$ Measured at or near the soil level.

${ }^{x}$ First-order branches (two branches per tree) were between 22 and 26 $\mathrm{mm}$ in diameter and arose directly from scaffold branches or trunk.

${ }^{\text {w}}$ All second-order branches that arose from two selected first-order branches per tree.

vThe number of first-order branches per $30 \mathrm{~cm}$ of trunk or scaffold. uThe number of second-order branches per $20 \mathrm{~cm}$ of first-order branch for $N n, N N$, and ST. On $d w d w$ and $n n$ trees, laterals per $10 \mathrm{~cm}$ of supporting branch.

${ }^{t}$ The angles from the trunk or scaffold of two first-order branches.

sThe angle from first-order branch for six second-order branches per tree.

rNodes on $20 \mathrm{~cm}$ of branch, measured at midbranch, for $N n, N N$, and ST. Total number of nodes on the branches of $d w d w$ and $n n$ trees.

${ }^{\mathrm{q}}$ Length and width at the widest dimension of six young fully expanded leaves sampled randomly throughout the canopy (10 trees).

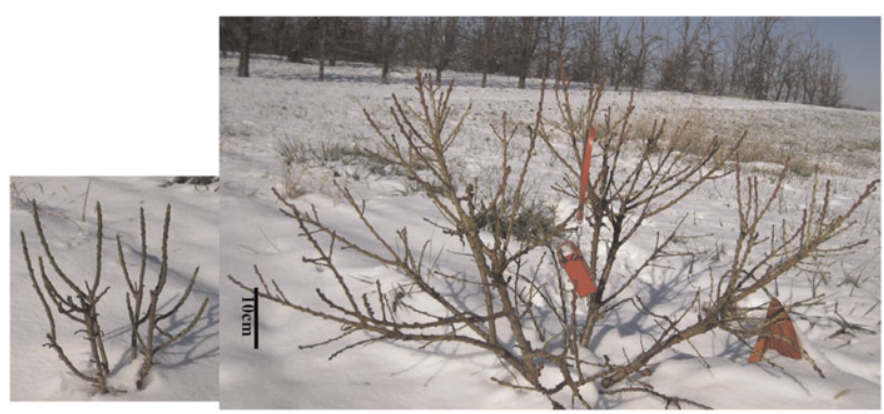

Fig. 2. Dwarf peach trees from self-pollination of 'A72' peach tree $n n$ (left) and from self-pollination of 'Valley Red' peach $(d w d w)$ (right) in the field, 2 years (Winter 2007).

and than $N N$ at 31 to $40 \mathrm{~cm}$ (data not presented). $N N$ and $\mathrm{ST}$ trees only differed in that ST trees had fewer sublaterals (Table 2).

Monet and Salesses (1975) reported that progeny derived from self-pollination of 'A72', based on tree height, segregated 

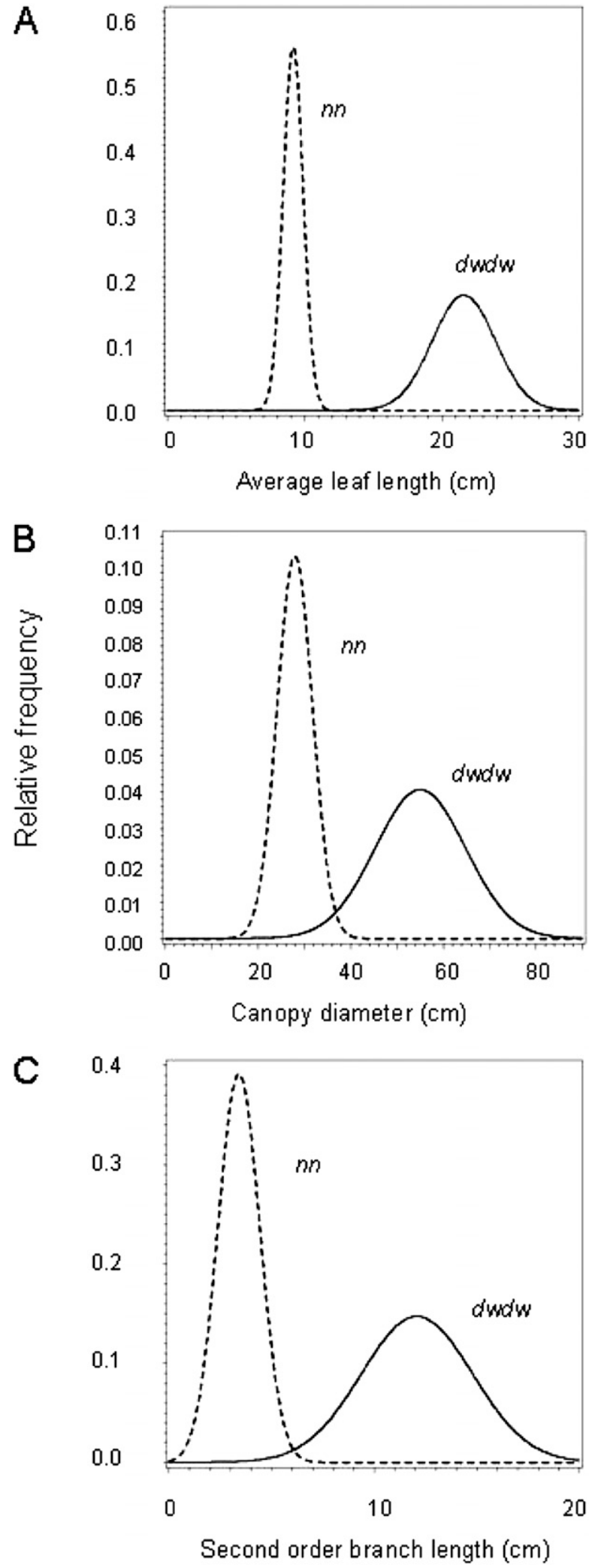

Fig. 3. The separation of 2-year-old $d w d w$ and $n n$ peach tree genotypes by leaf length (A), by canopy diameter (B), and by second-order branch length $(\mathbf{C})$. Plots are normal distributions centered at the values, which are the means for the respective tree types and having standard deviations for those respective types. The y-axis represents the relative frequency of observing a response (i.e., leaf length, second-order branch length, etc.) of that magnitude (i.e., value of the response)
Table 2. Comparison of first-order branch growth (branches arising from the main trunk) of $N N, N n$, and ST (standard) peach trees. Two first-order branches per tree were sampled from 10 randomly selected 2-year-old trees from each of the three phenotypes in Apr. 2008. The mean diameter of sampled branches at the point of removal from the tree was $23 \mathrm{~mm}$. Mean separations between columns by the Bonferroni least significant difference test.

\begin{tabular}{lcrr}
\hline & \multicolumn{3}{c}{ Tree type } \\
\cline { 2 - 4 } Growth characteristic & $N n^{\mathrm{z}}$ & \multicolumn{1}{c}{$N N^{\mathrm{z}}$} & $\mathrm{ST}^{\mathrm{y}}$ \\
\hline Branch length & $47.65 \mathrm{~b}$ & $86.75 \mathrm{a}$ & $88.10 \mathrm{a}$ \\
No. of laterals & $7.8 \mathrm{~b}$ & $15.05 \mathrm{a}$ & $14.15 \mathrm{a}$ \\
Number of sublaterals & $6.70 \mathrm{a}$ & $2.70 \mathrm{~b}$ & $0.10 \mathrm{c}$ \\
Average of lateral length & $35.53 \mathrm{a}$ & $22.75 \mathrm{~b}$ & $24.47 \mathrm{~b}$
\end{tabular}

"Progeny of self pollination of 'A72' peach.

'Progeny of self-pollination of 'Bounty' peach.

into a monogenic, incomplete dominance ratio of 1 dwarf:2 semidwarf: 1 standard, and the symbol " $n$ " was proposed for this locus. However, in our study, selfed 'A72' progeny planted at the same time and in the same field (155 trees) did not show this expected ratio based on height (Fig. 5). While the use of height for discriminating $N n$ from $N N$ trees was problematic, we noted that $N n$ trees typically displayed forked branching (FBR) (Drenou, 2000), which is associated with the abortion of an apical bud and the subsequent production of laterals below the aborted bud (Fig. 6). FBR was observed in selfed progeny of 'A72' and in hybrids between 'A72' and columnar trees (below).

FBR was evident in measurements of the average number of laterals taken every $10 \mathrm{~cm}$ from the main branch apex (Table 3 ; Fig. 4). Presumed $N n$ trees were denser branching in the apical branching zone, which had more laterals and sublaterals in discreet FBR areas. Lateral branch distribution was more uniform over the entire length of the supporting branch in $N N$ and ST trees. This different branching zone distribution (De Reffye et al., 1995) demonstrates the unique branching character of 'A72', which has not been previously described in peach. FBR can be used to distinguish $\mathrm{Nn}$ trees in 'A72' progenies and hybrids with 'A72'.

Based on FBR as a classification criterion, the average height of $N n$ trees was $142.2 \mathrm{~cm}$, about $84 \%$ of the average of $N N(168.1 \mathrm{~cm})$. These data indicate that although $N n$ trees are generally shorter than $N N$ trees, tree height might not be the most accurate discriminator, at least under the conditions of the study, which included relatively young trees and fertile soil.

Segregation studies. FBR was used to evaluate the segregation of 220 seedlings from self-pollination of 'A72'. Independent evaluations by three observers resulted in consistent classification of trees as FBR or non-FBR. The FBR characteristic allowed for the classification of this population into $1(N N): 2(N n): 1(n n)$ (Table 4). These data indicate that FBR is characteristic of the $n$ allele. Due to the extreme dwarfism of the $n n$ genotype, which is expressed in slow growth, short internodes, and sparse branching, it was not possible to distinguish FBR in this growth type.

Late bloom time also segregated in the 'A72' self-pollinated population. While $n n$ trees did not flower (we have observed that $n n$ and $d w d w$ seedlings flower in later years or sometimes do not flower at all), flowering time was useful for classifying $N n$ and $N N$ trees and produced a segregation ratio of $2(N n): 1$ 


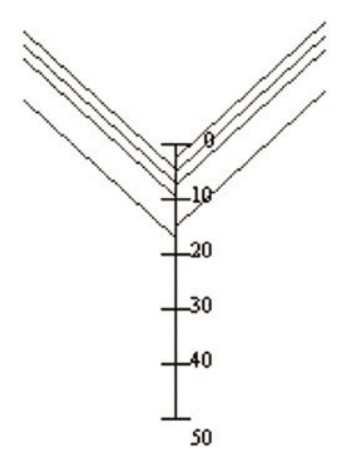

$\mathrm{Nn}$

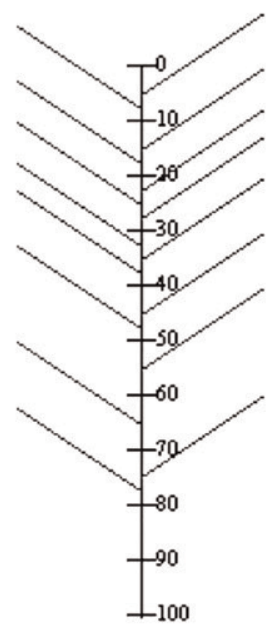

NN

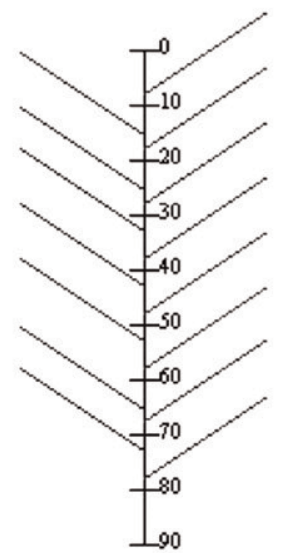

ST

A

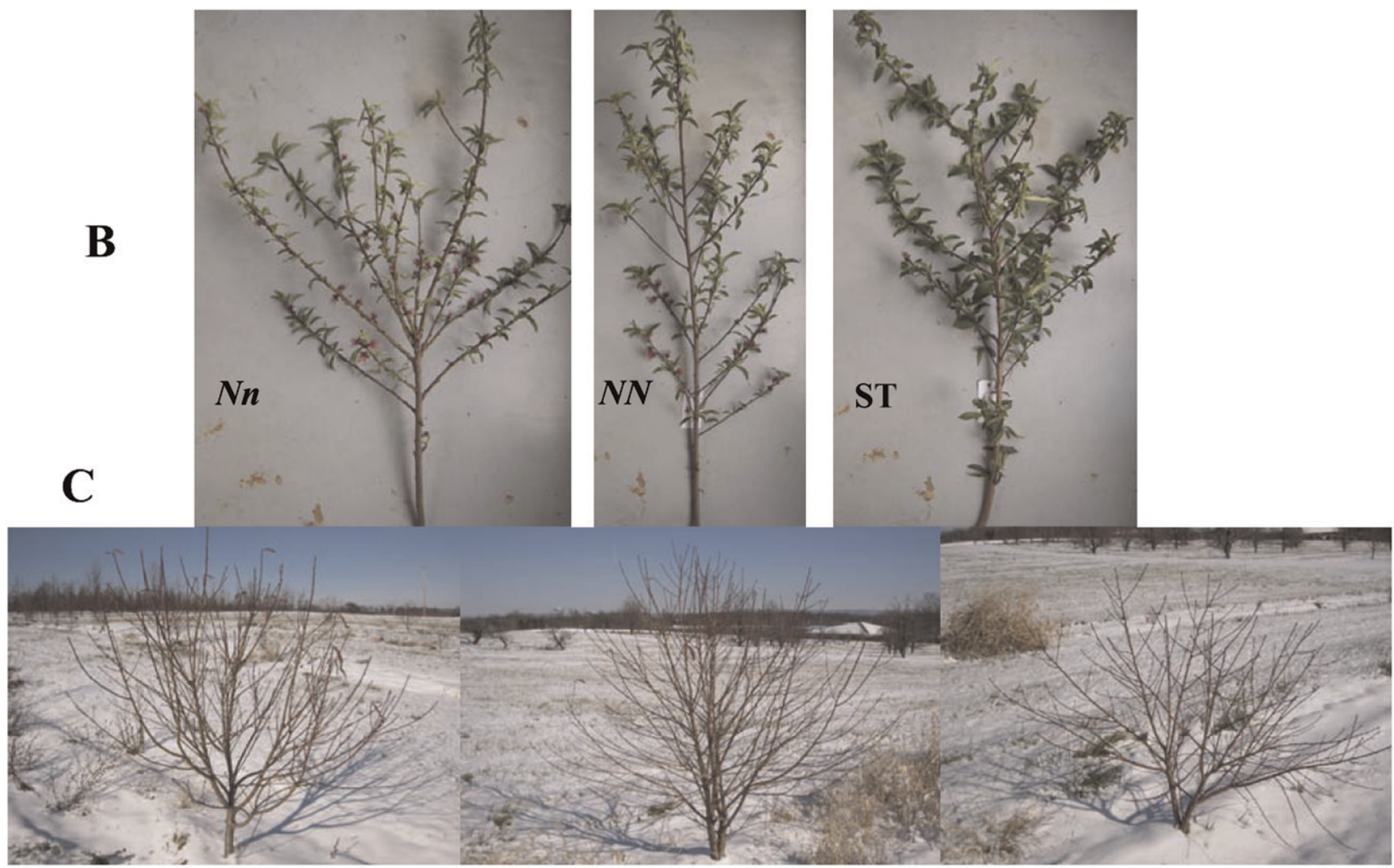

Fig. 4. Illustration of branch distribution in $N n$ and $N N$ trees from self-pollination of 'A72' and a standard (ST) peach tree from open pollination of 'Bounty' based on average measurement data (Branch length in centimeters is shown measured from the apex) (A). Typical branches sampled for measurement of $N n, N N$, and ST trees (Apr. 2008) (B). Nn, NN, and $S T$ trees in the field, 2 years (Winter 2007) (C).

$(N N)$ (Table 4). The parental 'A72' $(\mathrm{Nn})$ tree is late blooming. An association between 'A72' growth habit and flowering time has not been previously reported.

Hybridization of 'A72' $\times$ COLUMNAR PEACH TREes. As expected (Fig. 1), all hybrid progenies in the main (47 trees) and supporting (66 trees total) populations were columnar (pillar) (brbr). Red leaf color, a dominant trait (Blake, 1937), segregated as expected (Table 5). Using the forked branch character to identify $\mathrm{Nn}$, the progenies of the hybridization of KV000056 $\times$ KV981705 segregated into the expected ratio 1 $N N: 1 \mathrm{Nn}$ (Table 5). The average height of $N n$ was $132 \mathrm{~cm}$, which was about $45 \%$ of the average height of $N N(296 \mathrm{~cm})$. However, a wide range of height, from 64 to $235 \mathrm{~cm}$ and from 248 to $340 \mathrm{~cm}$ within $N n$ and $N N$ progenies, respectively, was 


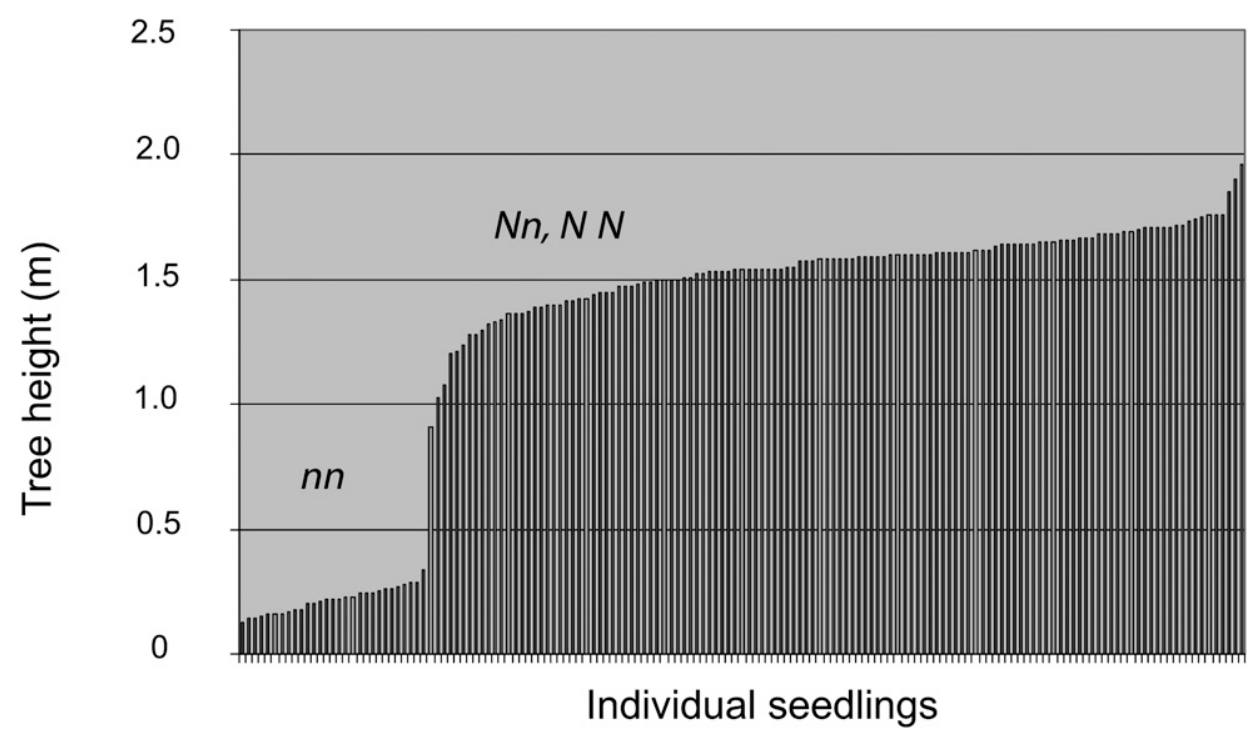

Fig. 5. Heights of peach tree seedlings from self pollination of 'A72' $(\mathrm{Nn})$ in the field in the third growing season (2008); $n n$ dwarf types clearly separate, but there is not a clear separation of $N n$ and $N N$ types. Population size was 155 seedlings.

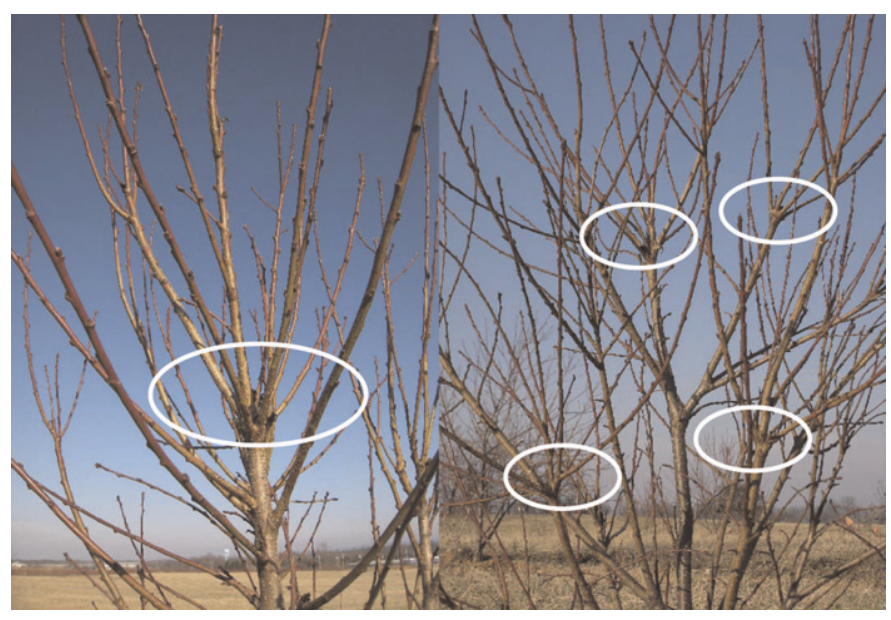

Fig. 6. Forked branching character in $\mathrm{Nn}$ seedling trees from self pollination of 'A72' peach. Examples of forked branching are circled.

observed. Tree height data did not produce meaningful chisquare ratios.

An additional six hybrid populations of columnar $\times$ ' $\mathrm{A} 72$ ' phenotypes (a total of 66 trees) also segregated as $1 \mathrm{NN}: 1 \mathrm{Nn}$ using the FBR characteristic (Table 6). The average height of $N n$ was $167 \mathrm{~cm}$, which is about $52 \%$ of the average height of $N N$ $(319.2 \mathrm{~cm})$.

\section{Discussion}

To our knowledge, only the original brief publication of Monet and Salesses (1975) describes the 'A72' peach and reports the inheritance of this phenotype as a monogenic incompletely dominant trait. Gradziel and Beres (1993) describe a phenotype (SD22-59) that may be the same mutation based on a monogenic incompletely dominant pattern of inheritance and an apparently similar tree form, although no direct comparisons between 'A72' and SD22-59 were made.
The distinguishing characteristic of 'A72' was reported to be its semidwarf growth habit, but specific measurements were not reported (Monet and Salesses, 1975). The SD22-59 mutant was described as producing a tree half the size of its normal appearing siblings, but it is not clear if the same mutation controls 'A72' and SD22-59. We found that under the conditions of our study, trees of the 'A72' phenotype were $84 \%$ of the height of the normal-appearing siblings. More striking than tree size was the unique FBR characteristic of 'A72'-type trees. This growth pattern produced trees with sparse branching for much of the supporting branch length, but a profusion of laterals in the apical zone that typically was associated with the demise of the apical bud of the supporting branch. Using FBR as a selection criterion for the progeny of 'A72', the segregation of this trait could be accurately described as monogenic incompletely dominant. Tree size alone was not sufficient to discern the inheritance of the 'A72' genotype. We also found that the 'A72' phenotype was associated with late flowering. It is not clear whether late flowering is linked with the 'A72' growth habit or if it is a pleiotropic effect of this mutant allele.

We showed that 'A72' can be combined with columnar growth habit to produce columnar trees with traits of 'A72', specifically $\mathrm{FBR}$, shorter stature, and late bloom. Tree stature of $N n$ genotypes

Table 3. Comparison of branching habit in progeny of 'A72' peach and seedlings from open pollination of 'Bounty', a standard size peach tree. Two first-order branches (arising from the trunk or major scaffold) per tree were sampled from 10 randomly selected trees from each of the three phenotypes NN, Nn, and ST in Apr. 2008 and the number of lateral branches counted. The mean diameter of sampled branches at the point of removal from the tree was $23 \mathrm{~mm}$. Mean separations between columns by the Bonferroni least significant difference test.

\begin{tabular}{llll}
\hline $\begin{array}{l}\text { Branch zone from } \\
\text { the branch apex }\end{array}$ & \multicolumn{3}{c}{ Tree type } \\
\cline { 2 - 4 }$N n^{\mathrm{y}}$ & \multicolumn{1}{c}{$N N^{\mathrm{y}}$} & $\mathrm{ST}^{\mathrm{x}}$ \\
\hline Branch zone 1 & $5.45 \mathrm{a}^{\mathrm{w}}$ & $2.15 \mathrm{~b}$ & $1.15 \mathrm{~b}$ \\
Branch zone 2 & $1.80 \mathrm{a}$ & $1.55 \mathrm{a}$ & $1.85 \mathrm{a}$ \\
Branch zone 3 & $0.40 \mathrm{~b}$ & $2.70 \mathrm{a}$ & $2.25 \mathrm{a}$ \\
Branch zone 4 & $0.15 \mathrm{~b}$ & $2.50 \mathrm{a}$ & $1.70 \mathrm{a}$ \\
Branch zone 5 & $0.06 \mathrm{~b}$ & $1.50 \mathrm{a}$ & $1.85 \mathrm{a}$ \\
Branch zone 6 & $0 \mathrm{~b}$ & $1.32 \mathrm{ab}$ & $2.05 \mathrm{a}$ \\
Branch zone 7 & $0 \mathrm{a}$ & $1.16 \mathrm{a}$ & $2.15 \mathrm{a}$ \\
Branch zone 8 & & $1.80 \mathrm{a}$ & $1.76 \mathrm{a}$ \\
Branch zone 9 & & $0.43 \mathrm{a}$ & $0.07 \mathrm{a}$ \\
Branch zone 10 & & $0.11 \mathrm{a}$ & $0 \mathrm{a}$ \\
\hline
\end{tabular}

Zone 1 = apical zone; each 10-cm increment from the apex was considered a "zone." $N n$ trees produced shorter branches and therefore did not produce zones 8 through 10 .

${ }^{\mathrm{y}} \mathrm{NN}$ and $\mathrm{Nn}$ were progeny of self pollination of 'A72' $(\mathrm{Nn})$.

'Seedlings of 'Bounty' peach.

${ }^{\mathrm{w}}$ Average number of lateral branches per $10 \mathrm{~cm}$ of branch length. 
Table 4. Chi-square analyses of the segregation of growth habit and flowering time in progeny of self-pollination of the 'A72' peach tree.

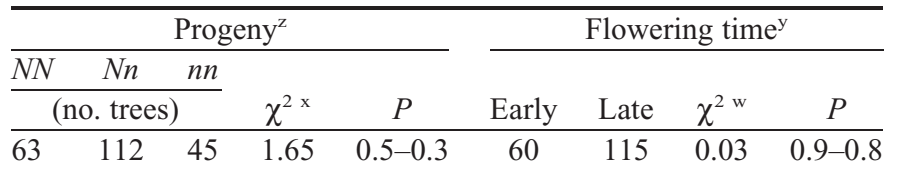

${ }^{\mathrm{z}} \mathrm{NN}=$ nonforked branch character, $\mathrm{Nn}=$ forked branch character, $n n=$ 'A72' dwarf.

${ }^{\mathrm{y}}$ Early $=$ early bloom $(100 \%$ open, some trees are already no petals $)$, late $=$ late bloom $(>50 \%$ of the flowers remained unopened but were viable).

${ }^{x}$ Chi-square values are based on the expected ratio of $1 \mathrm{NN}: 2 \mathrm{Nn}: 1 \mathrm{nn}$.

${ }^{\text {w }}$ Chi-square values are based on the expected ratio of 2 late: 1 early.

Table 5. Chi-square analyses of the segregation of growth habit, flowering time, and leaf color in progeny from hybridization of an 'A72' peach tree seedling with a red-leaf (Grgr) columnar $(b r b r)$ peach tree.

\begin{tabular}{|c|c|c|c|c|c|c|c|c|}
\hline \multirow[b]{3}{*}{ Cross } & & \multirow[b]{3}{*}{$\chi^{2 \times}$} & \multirow[b]{3}{*}{$P$} & \multicolumn{3}{|c|}{ Flowering time ${ }^{\mathrm{y}}$} & \multicolumn{2}{|l|}{ Leaf color } \\
\hline & $\mathrm{NN}^{\mathrm{z}}$ & & & Early Late & & & & \\
\hline & $\overline{\text { (no. trees) }}$ & & & $\overline{\text { (no. trees) }}$ & $\chi^{2 \mathrm{w}}$ & $P$ & Green Red $\chi^{2 v}$ & $P$ \\
\hline
\end{tabular}

\begin{tabular}{lllllllllllll}
\hline $\mathrm{KV} 000056 \times$ & 18 & 29 & 2.12 & $0.2-0.1$ & 24 & 23 & 0.02 & $0.9-0.8$ & 29 & 18 & 2.12 & $0.2-0.1$
\end{tabular}
KV981705

${ }^{\mathrm{z}} \mathrm{NN}=$ normal pillar, $\mathrm{Nn}=$ forked branch pillar.

${ }^{\mathrm{y}}$ Early $=$ early bloom $(100 \%$ open, some trees are already no petals $)$, late $=$ late bloom $(>50 \%$ of the flowers remained unopened but were viable).

${ }^{\mathrm{x}}$ Chi-square values for growth habit based on the expected ratio of 1 normal pillar (NNpipi): 1 forked branch (FBR) pillar (Nnpipi).

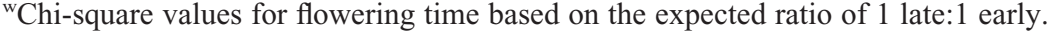

${ }^{\mathrm{v}} \mathrm{Chi}$-square values for leaf color based on the expected ratio of 1 green: 1 red.

Table 6. Chi-square analyses of the segregation of the forked branch (FBR) character in progenies of six crosses between 'A72' peach tree seedlings and red-leaf (Grgr) columnar $(b r b r)$ peach trees.

\begin{tabular}{|c|c|c|c|c|}
\hline \multirow[b]{2}{*}{ Parent } & \multicolumn{2}{|c|}{ Progeny (no. trees) ${ }^{\mathrm{z}}$} & \multirow[b]{2}{*}{$\chi^{2 \mathrm{y}}$} & \multirow[b]{2}{*}{$P$} \\
\hline & $\mathrm{Nn}$ & $N N$ & & \\
\hline $\begin{array}{l}\text { KV000056 × KV930465 } \\
\quad(N n b r b r g r g r \times N N b r b r g r g r)^{\mathrm{x}}\end{array}$ & 14 & 10 & 0.66 & $0.5-0.3$ \\
\hline $\begin{array}{l}\text { KV000009 } \times \text { KV } 980330 \\
\quad(\text { Nnbrbrgrgr } \times \text { NNbrbrgrgr })\end{array}$ & 3 & 9 & 3 & $0.1-0.05$ \\
\hline $\begin{array}{l}\text { ‘A72' pillar } \times \text { KV930408 } \\
(\text { Nnbrbrgrgr } \times \text { NNbrbrgrgr })\end{array}$ & 3 & 4 & 0.71 & $0.5-0.3$ \\
\hline $\begin{array}{l}\text { ‘A72' pillar } \times \text { KV981705 } \\
(\text { Nnbrbrgrgr } \times \text { NNbrbrGrgr })\end{array}$ & 3 & 5 & 0.12 & $0.8-0.7$ \\
\hline $\begin{array}{l}\text { KV000023 } \times \text { KV } 981705 \\
\quad(\text { Nnbrbrgrgr } \times \text { NNbrbrGrgr })\end{array}$ & 5 & 4 & 0.12 & $0.8-0.7$ \\
\hline $\begin{array}{l}\text { KV000009 } \times \text { KV } 981705 \\
\quad(\text { Nnbrbrgrgr } \times \text { NNbrbrGrgr })\end{array}$ & 1 & 5 & 2.66 & $0.2-0.1$ \\
\hline \multicolumn{5}{|l|}{$\mathrm{X}^{2}$} \\
\hline Pooled & & & 0.74 & $0.5-0.3$ \\
\hline Sum & & & 7.27 & $0.3-0.2$ \\
\hline Heterogeneity & & & 6.53 & $0.3-0.2$ \\
\hline
\end{tabular}

${ }^{\mathrm{z}} N n=$ forked branch character, $N N=$ normal pillar without forked branch.

${ }^{y} \mathrm{Chi}$-square values based on the expected frequency of $1 \mathrm{NN}: 1 \mathrm{Nn}$.

${ }^{x}$ Presumed genotypes based on pedigree, growth habit, and leaf color.

in 'A72' progeny from self pollination is more uniform than Nnbrbr progeny of columnar $\times$ 'A72.' We suspect that there is an interaction of minor genes that control tree growth that originate in the columnar germplasm because there is some variability in tree stature in seedling populations of columnar trees $(b r b r)$ ( The interaction of 'A72' with prowth habits requires further research. (y) for commercial peach production. While we nnot confirm the utility of 'A72' for commercial production we suggest that continued investigation of this growth we the shorter stature of the tree and a more readily manipulated by pruning to produce a desired tree To our knowledge, the effect of pruning on ' $\mathrm{A} 72$ ' is unexplored. The interaction with the columnar tree form asticity of peach tree structure that is available through breeding (Scorza et al., 1989, 2002). This plasticity challenges breeders and horticulturists to develop trees suitable to more economical and sustainable orchard practices.

Beyond commercial fruit production, there exists the potential of 'A72' as an ornamental, particularly combined with the columnar form. We found a wide range of tree sizes from these crosses with unique columnar forms. Dwarf trees $(n n)$ with smaller leaves than brachytic dwarf $(d w d w)$ trees present new opportunities for the development of DW trees for ornamental and home fruit garden cultivation. The 'A72' dwarf combined with pillar form may be useful for foundation or accent plantings, home fruit gardens, or bonsai cultivation. Unique tree form coupled with red leaf color could provide an ornamental appearance that lasts beyond the flowering season. Dwarf ornamental peaches may make good container plants that could be readily protected in the winter.

The late bloom characteristic of 'A72', not previously reported, is another useful trait of this genotype that requires further investigation. This characteristic may be useful in the avoidance of spring frost damage.

\section{Literature Cited}

Blake, M.A. 1937. Progress in peach breeding. Proc. Amer. Soc. Hort. Sci. 35:45-53.

Conners, C.H. 1928. Peach breeding. A summary of results. Proc. Amer. Soc. Hort. Sci. 17:108-115.

De Reffye, P., F. Houllier, F. Blaise, D. Barthelemy, J. Dauzat, and D. Auclair. 1995. A model simulating above and below-ground tree architecture with agroforestry applications. Agrofor. Syst. 30:175-197.

Drenou, C. 2000. Pruning trees: The problem of forks. J. Arboriculture 26:264-269.

Gradziel, T.M. and W. Beres. 1993. Semidwarf growth habit in clingstone peach with desirable tree and fruit qualities. HortScience 28:1045-1047.

Hansche, P.E. 1989. Three brachytic dwarf peach cultivars. Valley Gem, Valley Red, and Valley Sun. HortScience 24:707-709. 
Hooper, J. 1867. The Italian dwarf peach. Amer. J. Hort. 2:287-288.

Lammerts, W.E. 1945. The breeding of ornamental peaches for mild climates. I. Inheritance of tree and flower characters. Amer. J. Bot. 32:223-231.

Monet, R. and G. Salesses. 1975. Un nouveau mutant de nanisme chez le pécher. Annales Amélioration Plantes 25:353-359.

Scorza, R. 1984. Characterization of four distinct peach tree growth types. J. Amer. Soc. Hort. Sci. 109:455-457.

Scorza, R. and W.B. Sherman. 1996. Peach, p. 325-440. In: J. Janick and J.N. Moore (eds.). Fruit breeding, Vol. I. Tree and tropical fruits. Wiley, New York.
Scorza, R., D. Bassi, and A. Liverani. 2002. Genetic interactions of pillar (columnar), compact, and dwarf peach tree genotypes. J. Amer. Soc. Hort. Sci. 127:254-261.

Scorza, R., G.W. Lightner, and A. Liverani. 1989. The pillar peach tree and growth habit analysis of compact $\times$ pillar progeny. J. Amer. Soc. Hort. Sci. 114:991-995.

Strong, W.C. 1867. The van buren golden dwarf peach. Amer. J. Hort. 2:171-172.

Werner, D.J. and D.W. Cain. 1985. Cages for protection of tree fruit hybridizations. HortScience 20:450-451. 